\title{
Artemisia capillaris formula inhibits hepatic steatosis via an miR-122-induced decrease in fatty acid synthase expression in vivo and in vitro
}

\author{
LIYA LIU ${ }^{1,2}$, JINYAN ZHAO $^{1,2}$, YING LI $^{3}$, YUN WAN ${ }^{1,2}$, JIUMAO LIN $^{1,2}$, ALING SHEN $^{1,2}$, WEI XU $^{4}$, \\ HUANG $\mathrm{LI}^{4}$, YUCHEN ZHANG ${ }^{1,2}$, JIANFENG XU ${ }^{5}$, JUN PENG ${ }^{1,2}$ and ZHENFENG HONG ${ }^{1,2}$ \\ ${ }^{1}$ Academy of Integrative Medicine, Fujian University of Traditional Chinese Medicine; \\ ${ }^{2}$ Fujian Key Laboratory of Integrative Medicine on Geriatrics, Fujian University of Traditional Chinese Medicine, \\ Fuzhou, Fujian 350122; ${ }^{3}$ Department of Medicine, Xiamen Hospital of Traditional Chinese Medicine, \\ Jinshan Street Community Health Service, Xiamen, Fujian 361000; ${ }^{4}$ Department of Pharmacology, \\ Fujian University of Traditional Chinese Medicine, Fuzhou, Fujian 350122; \\ ${ }^{5}$ Fujian Guizhentang Pharmaceutical Co., Ltd., Quanzhou, Fujian 362142, P.R. China
}

Received January 8, 2015; Accepted March 5, 2015

DOI: $10.3892 / \mathrm{mmr} .2016 .5131$

\begin{abstract}
Non-alcoholic fatty liver disease (NAFLD) is a widespread health concern, and there is currently insufficient understanding regarding its pathogenesis and treatment. The present study aimed to explore the effects of Artemisia capillaris formula (ACF) on high-fat diet-induced hepatic steatosis and fatty acid-induced intracellular lipid accumulation, by micro (mi)RNA regulation. A total of 72 Sprague-Dawley rats were divided into six groups ( $n=12 /$ group). One group was designated as the control group and fed a normal diet, and the remaining five groups were allowed ad libitum access to a high-fat diet for eight weeks, in order to establish an NAFLD rat model. The rats were subsequently administered polyene phosphatidylcholine (PP; $0.076 \mathrm{~g} / \mathrm{kg}$ body weight/day), low dose of ACF ( $0.462 \mathrm{~g} / \mathrm{kg}$ body weight/day), middle dose of ACF $(0.924 \mathrm{~g} / \mathrm{kg}$ body weight/day) or high dose of ACF $(1.848 \mathrm{~g} / \mathrm{kg}$ body weight/day) intragastrically for four weeks. HepG2 human hepatocellular carcinoma cells were treated with oleic acid and palm acid, followed by treatment with various concentrations of ACF. Serum alanine transaminase (ALT), aspartate aminotransferase (AST), triglycerides (TG), total cholesterol (TC), high-density lipoprotein cholesterol (HDL-C), low-density lipoprotein cholesterol (LDL-C), and steatotic HepG2 human liver carcinoma cell TC and TG levels were measured. ACF and PP
\end{abstract}

Correspondence to: Professor Zhenfeng Hong, Academy of Integrative Medicine, Fujian University of Traditional Chinese Medicine, Building 301, 1 Huatuo Road, Minhou Shangjie, Fuzhou, Fujian 350122, P.R. China

E-mail: zhenfeng.hong@yahoo.com

Key words: Artemisia capillaris, non-alcoholic fatty liver disease, microRNA-122, fatty acid synthase treatments attenuated high-fat diet-induced hepatic steatosis and fatty acid-induced intracellular lipid accumulation. A modified high-fat diet significantly increased ALT, AST, TG, TC, LDL-C levels and decreased HDL-C levels. Treatment with $\mathrm{ACF}$ and $\mathrm{PP}$ abrogated the increase in liver enzymes and TG, TC and LDL-C levels, but did not influence HDL-C levels in a high-fat diet induced rat model of steotosis. Steatotic HepG2 cells exhibited significantly increased levels of both TG and TC. Treatment with ACF significantly decreased TC and TG levels in vivo, and ACF and PP treatment decreased the expression levels of fatty acid synthase (FASN) and increased miR-122 in vivo and in vitro. In conclusion, these results suggested that ACF may inhibit hepatic steatosis via miR-122-induced downregulation of FASN in vivo and in vitro.

\section{Introduction}

Non-alcoholic fatty liver disease (NAFLD) is a type of liver disorder characterized by the absence of a history of excessive alcohol consumption, with steatosis and lipoidosis. NAFLD is the most common cause of chronic liver disease in Western countries, and is estimated to influence $\sim 30 \%$ of the general population $(1,2)$. Various lifestyle-associated diseases, including metabolic syndrome, obesity, type 2 diabetes, arterial hypertension and hyperlipidemia have been shown to be associated with NAFLD (3-5); however, the cellular mechanisms underlying the development and progression of NAFLD have remained elusive.

Research regarding the pathogenic mechanisms of NAFLD has identified signal transduction and post-translational protein modification, as well as transcriptional activation and repression processes (6). Included in the latter category, microRNAs (miRNAs) are short ( 19-24 nucleotide) non-protein-coding RNAs that regulate hundreds of targets, primarily through translational inhibition or messenger RNA (mRNA) degradation $(6,7)$. Consequently, miRNAs are able to regulate various biological processes, including cell proliferation, apoptosis and metabolism. It has previously been suggested that 
miR-122 may regulate the majority of target genes involved in lipid and cholesterol metabolism (8). Fatty acid synthase (FASN) is one of the known target genes of miR-122 $(9,10)$. The process of fatty acid synthesis is highly coordinated and involves numerous enzymes. Reduced expression of FASN may therefore significantly reduce the levels of triglycerides in vivo, facilitating the prevention and treatment of fatty liver disease (9).

Pharmacological agents used in Western medicine to treat NAFLD have a low efficacy, and lipid-regulating pharmaceuticals are frequently used as adjunctive therapy $(11,12)$. Antioxidants, including vitamins B, C and E, lecithin, thiazolidinediones and silymarin are often used to protect liver tissue; however, these agents lack specificity in the treatment of fatty liver diseases, and certain synthetic supplements have the potential for liver toxicity $(13,14)$. Natural products, including Traditional Chinese Medicines, have long been considered as alternative medicines. Nevertheless, numerous formulas have been shown to possess beneficial therapeutic effects against various diseases, including NAFLD (15).

Artemisia capillaris formula (ACF) is a traditional Chinese formula, which has a long history of clinical use for the treatment of NAFLD in China. Preliminary research by our group in a rat model of NAFLD demonstrated that ACF was able to significantly decrease the liver weight and alter the serum free fatty acid levels of the rats, thus suggesting that ACF may be a useful therapy for NAFLD (16). However, the mechanisms underlying its anti-NAFLD activity remain to be elucidated.

The present study used a rat model of diet-induced NAFLD, as well as HepG2 human liver carcinoma cells cultured with a high concentration of free fatty acid (HFFA) to investigate whether miRNAs contribute to the pathogenesis of NAFLD. Polyene phosphatidylcholine (PP) is a hepatoprotective therapeutic agent that accelerates choleresis $(17,18)$, in the present study, PP served as a positive control.

\section{Materials and methods}

Preparation and content assay of ACF. ACF was provided by the Academy of Pharmacology of Fujian Chinese Medical University (Fuzhou, China). For the animal experiments, ACF powder was dissolved in physiological saline to a working concentration of $500 \mathrm{mg} / \mathrm{ml}$. For the cell-based experiments, a stock solution of ACF $(1 \mathrm{~g} / \mathrm{ml})$ was freshly prepared by dissolving ACF powder in double distilled $\mathrm{H}_{2} \mathrm{O}$ to a concentration of $1 \mathrm{~g} / \mathrm{ml}$, which was subsequently stored at $-20^{\circ} \mathrm{C}$. Working concentrations of ACF $(1.25 \mathrm{mg} / \mathrm{ml}$ and $2.5 \mathrm{mg} / \mathrm{ml}$ ) were prepared by diluting the stock solution in culture medium of Dulbecco's modified Eagle's medium (DMEM) supplemented with $10 \%$ (v/v) fetal bovine serum (FBS) and $100 \mathrm{U} / \mathrm{ml}$ penicillin and $100 \mu \mathrm{g} / \mathrm{ml}$ streptomycin (all obtained from Thermo Fisher Scientific, Inc., Waltham, MA, USA).

Reagents. TRIzol ${ }^{\circledR}$ reagent, M-MLV First-Strand cDNA Synthesis kit and Taq DNA Polymerase were obtained from Invitrogen (Thermo Fisher Scientific, Inc.). Assay kits for alanine aminotransferase (ALT), aspartate transaminase (AST), triglyceride (TG), total cholesterol (TC), high-density lipoprotein cholesterol (HDL-C), low-density lipoprotein cholesterol (LDL-C) activity and oil red staining were obtained from the Jiancheng Institute of Biotechnology (Nanjing, China). PP was obtained from the Tonghua Dongbao Pharmaceutical Co., Ltd. (Tonghua, China). Trypsin-EDTA and Fast SYBR ${ }^{\circledR}$ Green Master Mix were purchased from Thermo Fisher Scientific, Inc.. Rabbit polyclonal FASN (cat. no. $3180 ; 1: 1,000$ ) and $\beta$-actin (cat. no. 4970; $1: 2,000)$ primary antibodies, and horseradish peroxidase (HRP)-conjugated secondary antibodies (cat. no. 7074) were obtained from Cell Signaling Technology, Inc. (Danvers, MA, USA). All other chemicals, unless otherwise stated, were obtained from Sigma-Aldrich (St. Louis, MO, USA).

Animal model and treatment protocols. Male 8-week-old Sprague-Dawley (SD) rats (Slike Co., Ltd., Shanghai, China), weighing $200 \pm 10 \mathrm{~g}$, were housed five per cage in an environmentally controlled room $\left(22 \pm 1^{\circ} \mathrm{C}\right)$ with $40-60 \%$ relative humidity. Air exchange occurred 12-18 times/h and a 12:12 h artificial light/dark cycle of 150-300 lux was maintained. The rats were given ad libitum access to food and water. All experiments using animals were approved by the Animal Ethics Committee of the Fujian Institute of Traditional Chinese Medicine (Fuzhou, China). Experimental procedures were conducted in accordance with the Guidelines for Animal Experimentation of Fujian University of Traditional Chinese Medicine.

To establish the animal model, 72 rats were randomly divided into six groups (12 rats/group), with one group of rats used as a control and fed a normal diet that consisted of $\geq 18 \%$ total protein, $\geq 5 \%$ total fat, $\leq 5 \%$ fiber and $\leq 8 \%$ crude ash. The remaining rats were allowed ad libitum access to a high-fat diet (HFD) for eight weeks. The HFD recipe conformed to NAFLD models in SD rats $(19,20)$, and consisted of: $87.3 \%$ basal fodder, $10 \%$ lard, $2 \%$ cholesterol and $0.7 \%$ swine bile salt. Following an eight-week feeding period, the HFD-fed rats were randomly divided into five groups: The model group (model), PP-treated group (0.076 g/kg body weight/day), ACF high-dose group (1.848 g/kg body weight/day), ACF middle-dose group $(0.924 \mathrm{~g} / \mathrm{kg}$ body weight/day) and $\mathrm{ACF}$ low-dose group ( $0.462 \mathrm{~g} / \mathrm{kg}$ body weight/day) (12 rats/group). $\mathrm{ACF}$ and PP were administered as previously described (21). The control and model groups received equal volumes of distilled water $(<5 \mathrm{ml})$. The body weight and food uptake of the rats was recorded weekly. Following four weeks of treatment, the rats were subjected to $4 \mathrm{~h}$ food depravation and subsequently sacrificed by administration of $45 \mathrm{mg} / \mathrm{kg}$ pentobarbital. Blood samples were collected from the aorta abdominalis for the AST, ALT, TG, TC, HDL-C and LDL-C assays. The samples were incubated at room temperature for $2 \mathrm{~h}$ and centrifuged at $3,000 \mathrm{x} \mathrm{g}$ at $4^{\circ} \mathrm{C}$ for $20 \mathrm{~min}$ to separate the serum, which was collected and stored at $-20^{\circ} \mathrm{C}$. Livers were rapidly dissected, and a section of each liver was cut and fixed in formaldehyde saline (4\%) solution for histological analysis; the remaining tissue was snap frozen in liquid nitrogen and stored at $-80^{\circ} \mathrm{C}$ prior to use.

Histological examination. The liver tissue for histological evaluation was immediately fixed in $10 \%$ buffered formalin for pathological analysis. Formalin-fixed liver tissue was 
paraffin-embedded and 4-5-mm sections were prepared and subsequently stained with hematoxylin and eosin. Histological evaluation was performed twice by a pathologist blinded to the treatments on two separate occasions. A semi-quantitative scoring system was used to assess the severity of hepatic steatosis, and the inflammatory cell infiltration in 10 different fields per section (magnification, x100; DMI 6000; Leica Microsystems GmbH, Wetzlar, Germany) (22). Briefly, the following criteria were used for scoring hepatic steatosis: Grade 0 (-), no fat; grade 1 (+), fatty hepatocytes occupying $<33 \%$ of the hepatic parenchyma; grade $2(++)$, fatty hepatocytes occupying 33-66\% of the hepatic parenchyma; grade $3(+++)$, fatty hepatocytes occupying $>66 \%$ of the hepatic parenchyma (19).

Biochemical assays. Serum was separated by centrifugation at 3,000 x g for $30 \mathrm{~min}$ and analyzed immediately. Serum AST, ALT, TG, TC, HDL-C and LDL-C levels were determined by spectrophotometry (BA-88A; Mindray Bio-Medical Electronics Co., Ltd., Shenzen, China). The serum sample (2.5 $\mu \mathrm{l}$ ) was mixed with $80 \mu \mathrm{l}$ of solution R1 from commercially available kits (Nanjing Jiancheng Bioengineering Institute, Nanjing, China). This was incubated for $5 \mathrm{~min}$ at $37^{\circ} \mathrm{C}$ and absorbance was measured (A1) at a wavelength of $546 \mathrm{~nm}$. Solution R2 (60 $\mu \mathrm{l})$ was added to the tube and incubated for $5 \mathrm{~min}$ at $37^{\circ} \mathrm{C}$ and absorbance was measured (A2) at a wavelength of $546 \mathrm{~nm}$. The levels in the serum $(\mathrm{mmol} / \mathrm{l})$ were calculated using an equation: [(Sample A2 - sample A1) - (blank A2 - blank A1) / [(standard A2 - standard A1) - (blank A2 - blank A1)] x calibration sample value. The activity of AST and ALT (U/l) were calculated using a standard curve.

Immunohistochemical staining. Following fixation with $10 \%$ buffered formalin for $12 \mathrm{~h}$, the liver samples were conventionally processed, in order to prepare paraffin-embedded liver section slides. The slides were incubated with antigen retrieval solution $\left(10 \mathrm{mM}\right.$ sodium citrate; $\mathrm{pH} \mathrm{6.0)}$ at $95^{\circ} \mathrm{C}$ for $10 \mathrm{~min}$, rinsed in cold water for $10 \mathrm{~min}$ and the endogenous peroxidase activity was quenched using hydrogen peroxide. Following blocking for non-specific proteins using normal serum in phosphate-buffered saline (PBS; 0.1\% Tween-20), the slides were incubated with rabbit polyclonal antibodies targeting FASN (1:200 dilution) at $4^{\circ} \mathrm{C}$ overnight. The slides were then washed with PBS three times each for $5 \mathrm{~min}$, and incubated with a biotinylated secondary antibody for $30 \mathrm{~min}$ at room temperature. Subsequently, the slides were incubated with horseradish peroxidase-conjugated streptavidin at $37^{\circ} \mathrm{C}$ for $20 \mathrm{~min}$ (Dako, Glostrup, Denmark), and washed with PBS three times each for 5 min. The slides were then incubated with diaminobenzidine for 30-60 sec at room temperature as the chromogen, followed by further counterstaining with diluted Harris hematoxylin for 20-30 sec at room temperature. Following staining, five high-power fields (magnification, x400; DMB0004 LED; Leica Microsystems $\mathrm{GmbH}$ ) were randomly selected from each slide, and the average proportion of positive cells in each field was counted using a true color multi-functional cell image analysis management system (Image-Pro Plus 6.0; Media Cybernetics, Rockville, MD, USA). To rule out any nonspecific staining, PBS was used instead of the primary antibody as a negative control.
Cell culture. HepG2 human liver carcinoma cells were obtained from the Cell Bank of Chinese Academy of Science (Shanghai, China). The cells were cultured in DMEM supplemented with $10 \%$ (v/v) FBS, $100 \mathrm{U} / \mathrm{ml}$ penicillin and $100 \mu \mathrm{g} / \mathrm{ml}$ streptomycin at $37^{\circ} \mathrm{C}$ in a humidified incubator containing $5 \% \mathrm{CO}_{2}$.

To induce cellular fat overloading, the following steps were performed in accordance with previously established methods $(23,24)$. Briefly, stock solutions of $0.6 \mathrm{~mol} / 1$ oleic acid $(\mathrm{OA})$ and $0.6 \mathrm{~mol} / \mathrm{l}$ palm acid (PA) were prepared in dimethyl sulfoxide. Subsequently, HepG 2 cells at $75 \%$ confluence were exposed to a mixture of $\mathrm{OA}$ and $\mathrm{PA}$ at a final ratio of 2:1, and final concentration of $1 \mathrm{mmol} / 1$ in complete DMEM for $24 \mathrm{~h}$ at $37^{\circ} \mathrm{C}(24,25)$. For ACF treatment, the cells were treated with $\mathrm{ACF}(1.25$ and $2.5 \mathrm{mg} / \mathrm{ml})$ for $24 \mathrm{~h}$ at $37^{\circ} \mathrm{C}$ in $5 \% \mathrm{CO}_{2}$. The induction parameters were optimized in a preliminary test, in order to achieve maximal fat overaccumulation with minimal cytotoxic and apoptotic effects of HFFA.

Oil red $O$ staining. HepG2 cells were seeded into 12-well plates at a density of $6 \times 10^{4}$ cells/well in $1 \mathrm{ml}$ complete DMEM and incubated overnight at $37^{\circ} \mathrm{C}$ in $5 \% \mathrm{CO}_{2}$. Once the steatotic cell model had been established for $24 \mathrm{~h}$, the cells were treated with ACF (1.25 and $2.5 \mathrm{mg} / \mathrm{ml})$ for $24 \mathrm{~h}$ at $37^{\circ} \mathrm{C}$ in $5 \% \mathrm{CO}_{2}$, and the lipid content in HepG2 cells was subsequently determined using an oil red $\mathrm{O}$ staining kit, according to the manufacturer's instructions. Briefly, at the end of treatment, the cells were fixed with $4 \%$ polyoxymethylene for $10 \mathrm{~min}$, incubated in oil red solution for $15 \mathrm{~min}$ in the dark at room temperature and then incubated with Gill's or Mayer's hematoxylin for $30 \mathrm{sec}$ at room temperature. Images of stained tissue were recorded using a phase-contrast microscope (DMI 6000; Leica Microsystems GmbH). Images were captured at a magnification of $\mathrm{x} 400$.

TC and TG analysis. HepG2 cells were seeded into six-well plates at a density of $1.5 \times 10^{5}$ cells/well in $2 \mathrm{ml}$ complete DMEM and incubated overnight at $37^{\circ} \mathrm{C}$ in $\mathrm{CO}_{2}$. Once the steatotic cell model had been established for $24 \mathrm{~h}$, the cells were treated with various concentrations of ACF (1.25 and $2.5 \mathrm{mg} / \mathrm{ml})$ for $24 \mathrm{~h}$ at $37^{\circ} \mathrm{C}$ in $5 \% \mathrm{CO}_{2}$. The cells were collected via scraping in PBS and disrupted by sonication (Sonics \& Materials, Inc., Newtown, CT, USA), followed by centrifugation at 3,000 $\mathrm{x}$ g for $5 \mathrm{~min}$. Subsequently, the supernatants were collected and the TG content was measured using a commercial kit, based on the phosphoglycerol oxidase/peroxidase enzymatic reaction according to the manufacturer's instructions.

Reverse transcription-quantitative polymerase chain reaction $(R T-q P C R)$. Total RNA was extracted from the liver tissue and HepG2 cells using TRIzol ${ }^{\circledR}$ reagent. Oligo(dT)-primed RNA (1 $\mu \mathrm{g})$ was reverse-transcribed using SuperScript II Reverse Transcriptase, according to the manufacturer's instructions. The obtained cDNA was used to determine the relative mRNA expression levels of precursor miR-122, FASN and GAPDH by RT-qPCR. RT-qPCR was performed using SYBR Green I Master mix in an ABI 7500 Fast instrument (Applied Biosystems; Thermo Fisher Scientific, Inc.) under conditions as follows: Initial denaturation at $95^{\circ} \mathrm{C}$ for $20 \mathrm{sec}$; and 40 cycles of denaturation at $95^{\circ} \mathrm{C}$ for $3 \mathrm{sec}$ and $60^{\circ} \mathrm{C}$ for $40 \mathrm{sec}$. RT-qPCR reactions were conducted according to the 
A

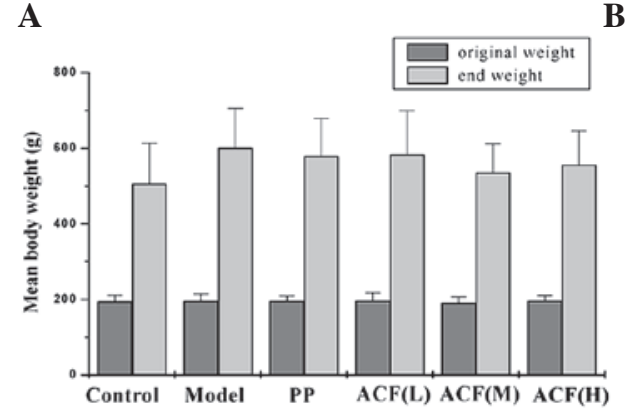

B

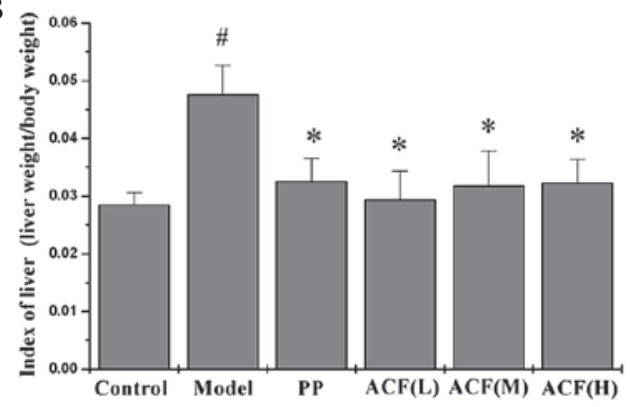

Figure 1. Effects of ACF on (A) body weight and (B) liver toxicity index of Sprague-Dawley rats fed a high-fat diet. Data represent the mean \pm standard deviation ( $\mathrm{n}=12$ /group). ${ }^{*} \mathrm{P}<0.05$, as compared with the control group; ${ }^{*} \mathrm{P}<0.05$, as compared with the model group. ACF(L), low-dose Artemisia capillaris formula group; $\mathrm{ACF}(\mathrm{M})$, middle-dose $\mathrm{ACF}$ group; $\mathrm{ACF}(\mathrm{H})$, high-dose $\mathrm{ACF}$ group; $\mathrm{PP}$, polyene phosphatidylcholine.
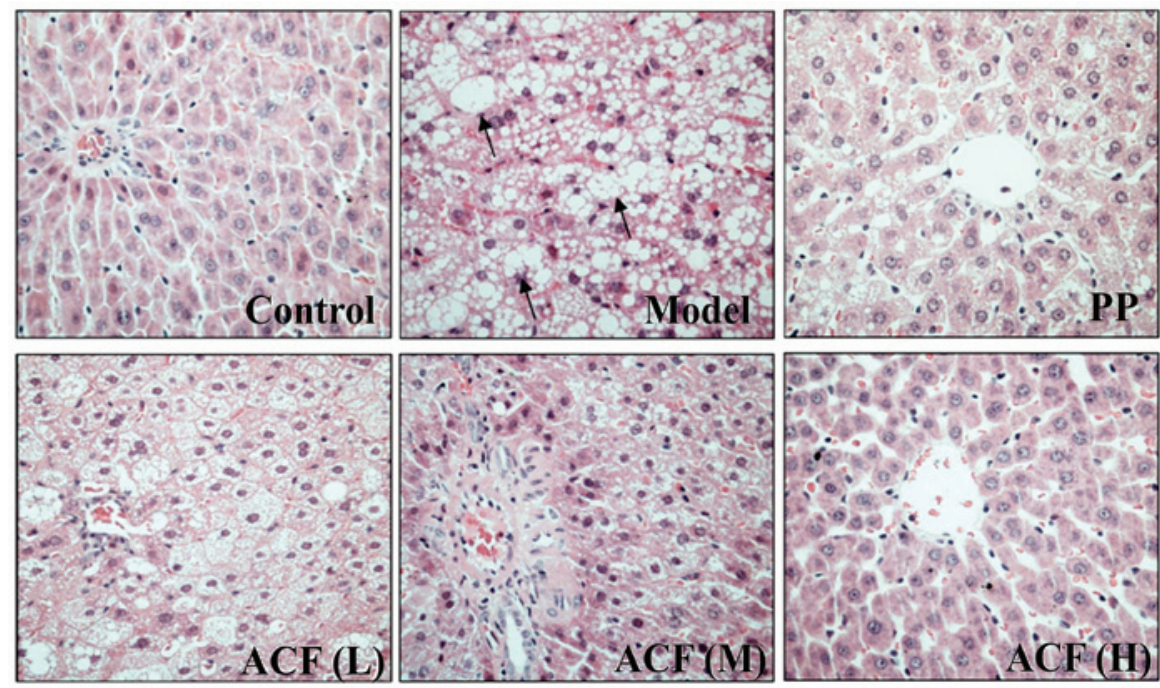

Figure 2. Effects of ACF on the hepatic morphology of liver tissue from Sprague-Dawley rats fed a high-fat diet. Control, (-) no liver fat; model, (+++) fatty hepatocytes occupying $>66 \%$ of the hepatic parenchyma, the rats demonstrated increased fat accumulation and developed steatohepatitis, which was characterized by hepatocyte ballooning, scattered lobular inflammatory cell infiltration and inflammatory foci (as indicated by the black arrow); PP, (+) fatty hepatocytes occupying $<33 \%$ of the hepatic parenchyma; $\mathrm{ACF}(\mathrm{L}),(++)$ fatty hepatocytes occupying $33-66 \%$ of the hepatic parenchyma; $\mathrm{ACF}(\mathrm{M}),(++)$ fatty hepatocytes occupying $33-66 \%$ of the hepatic parenchyma, which was similar to the effects of $\mathrm{ACF}(\mathrm{L}) ; \mathrm{ACF}(\mathrm{H}),(+)$ fatty hepatocytes occupying $<33 \%$ of the hepatic parenchyma, which was similar to the effects of PP treatment. ACF and PP treatment ameliorated hepatic steatosis and necroinflammation in the rats fed a high fat diet. Data shown represent the mean \pm standard deviation ( $\mathrm{n}=12$ /group). Representative images were captured at magnification, $\mathrm{x} 400$. $\mathrm{ACF}(\mathrm{L})$, low dose Artemisia capillaris formula group; $\mathrm{ACF}(\mathrm{M})$, middle dose $\mathrm{ACF}$ group; $\mathrm{ACF}(\mathrm{H})$, high dose $\mathrm{ACF}$ group; $\mathrm{PP}$, polyene phosphatidylcholine.

manufacturer's instructions. Gene expression levels were determined as $\Delta \mathrm{Ct}=(\mathrm{Ct}($ sample $)-\mathrm{Ct}(\mathrm{GAPDH}))$ and relative quantities between different samples were determined as $\Delta \Delta \mathrm{Ct}=[\Delta \mathrm{Ct}$ (sample1) $-\Delta \mathrm{Ct}($ sample2) $]$ (26). RT-PCR was performed using Dream Taq Green PCR Master mix and a GeneAmp PCR System 9600 (Applied Biosystems; Thermo Fisher Scientific, Inc.) under conditions as follows: Initial denaturation at $95^{\circ} \mathrm{C}$ for $5 \mathrm{~min} ; 35$ cycles of denaturation at $95^{\circ} \mathrm{C}$ for $30 \mathrm{sec}$, annealing at $60^{\circ} \mathrm{C}$ for $30 \mathrm{sec}$, elongation at $72^{\circ} \mathrm{C}$ for $1 \mathrm{~min}$; and a final elongation step at $72^{\circ} \mathrm{C}$ for $10 \mathrm{~min}$. The PCR products were separated by electrophoresis on a $1.5 \%$ agarose gel made using agarose obtained from Thermo Fisher Scientific, Inc.. PCR reactions were conducted according to the manufacturer's protocol. GAPDH and U6 were amplified as a control. The primers used were supplied by Shanghai Generay Biotech Co., Ltd. (Shanghai, China) and the sequences were as follows: Sense, 5'-AGATCCACAACGGAT-3' and antisense, 5'-TCCCTCAAGATTGTCAGCAA-3' for rat GAPDH (308 bp); sense, 5'-CCTTAGTACTGCGTGGTCGTAT-3' and antisense, 5'-CAGAGGGTGCTTGTTAGAAAGAT-3' for rat FASN (301 bp); sense, 5'-CTCGCTTCGGCAGCACA-3' and antisense, 5'-AACGCTTCACGAATTTGCGT-3' for human U6 (130 bp); sense, 5'-CCTTAGCAGAGCTCTGGAGTG TGAC-3' and antisense, 5'-GCCTAGCAGTAGCTGTTTAGT GTGA-3' for human pre-miR-122 (85 bp); and sense, 5'-CAG AGCAGCCATGGAGGAG-3' and antisense, 5'-CATCGT CCGTGACCATGTCC-3' for human FASN (119 bp).

Western blot analysis. The treated cells were lysed using mammalian cell lysis buffer containing protease and phosphatase inhibitor cocktails. The cell lysates were separated by $8 \%$ SDS-PAGE at $80 \mathrm{~V}$ for $0.5 \mathrm{~h}$ and $100 \mathrm{~V}$ for $2 \mathrm{~h}$, and were then electrophoretically transferred onto polyvinylidene fluoride membranes. The membranes were blocked for $2 \mathrm{~h}$ with blocking solution at room temperature, washed in Tris-buffered saline with $0.25 \%$ Tween-20 (TBS-T) and exposed to primary antibodies targeting FASN (1:1,000 dilution) overnight at $4^{\circ} \mathrm{C}$. $\beta$-actin (1:1,000 dilution) was measured as an internal control for 

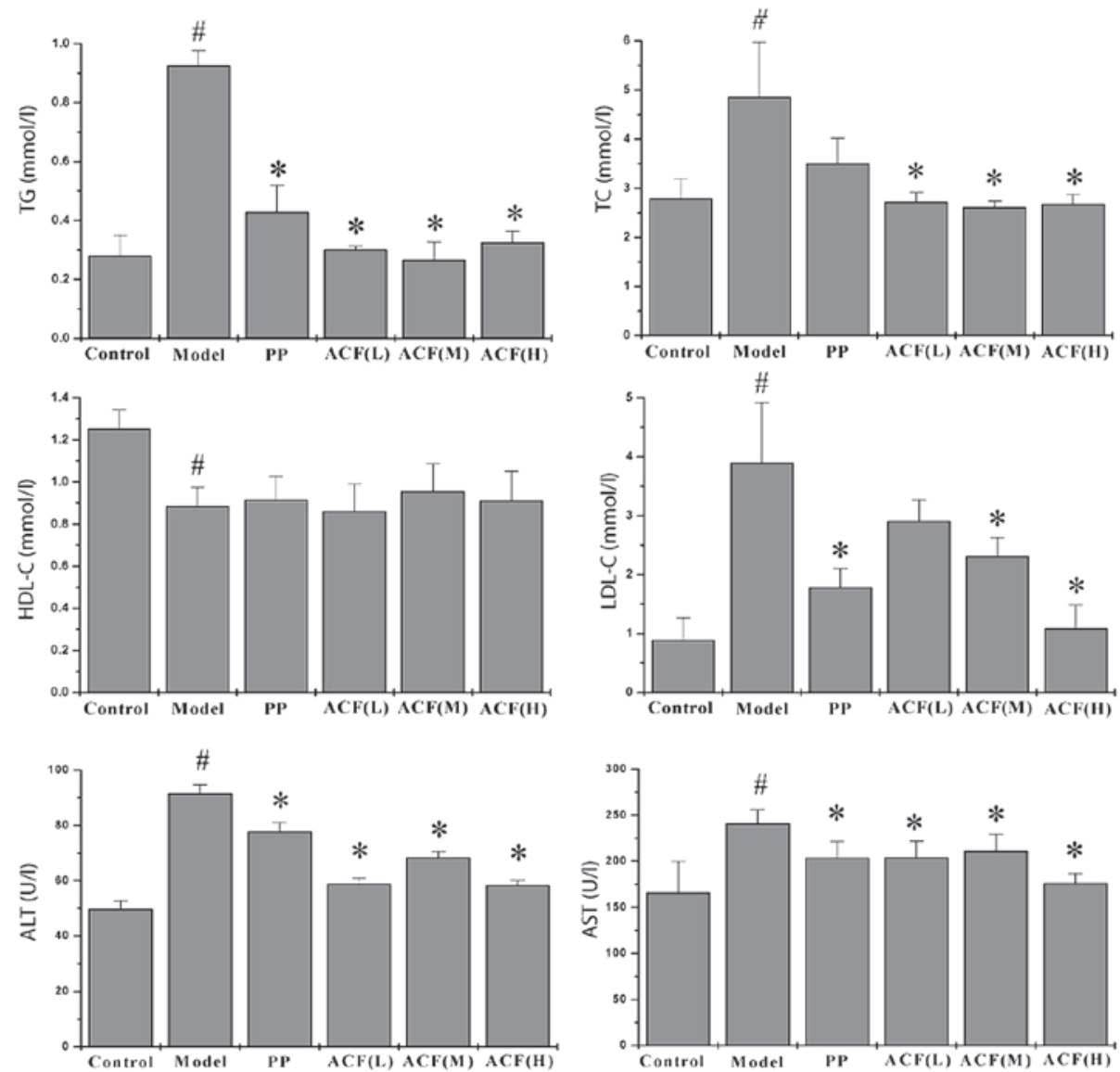

Figure 3. Effects of ACF on high-fat diet-induced increases in hepatic enzymes and serum lipids in the various Sprague-Dawley rat groups. Data represent the mean \pm standard deviation ( $\mathrm{n}=12$ /group). ${ }^{*} \mathrm{P}<0.05$, as compared with the control; ${ }^{*} \mathrm{P}<0.05$, as compared with the model group. PP, polyene phosphatidylcholine; $\mathrm{ACF}(\mathrm{L})$, low-dose Artemisia capillaris formula group; $\mathrm{ACF}(\mathrm{M})$, middle-dose $\mathrm{ACF}$ group; $\mathrm{ACF}(\mathrm{H})$, high-dose ACF group; ALT, alanine aminotransferase; AST, aspartate transaminase; TG, triglyceride; TC, total cholesterol; HDL-C, high-density lipoprotein cholesterol; LDL-C, low-density lipoprotein cholesterol.

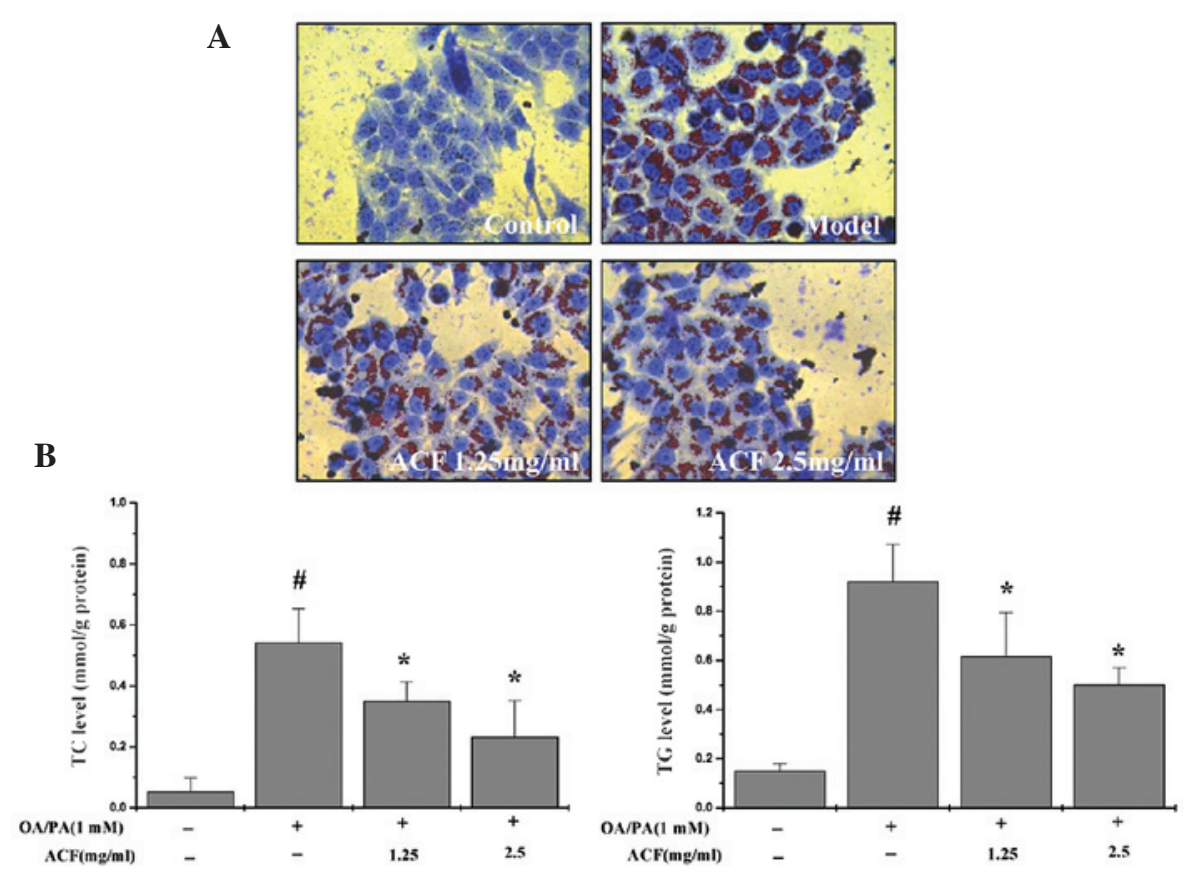

Figure 4. Effects of ACF on steatotic HepG2 human liver carcinoma cell morphology. HepG2 cells were cultured with normal medium (control) or a high concentration of HFFA (model) for $24 \mathrm{~h}(1.25 \mathrm{and} 2.5 \mathrm{mg} / \mathrm{ml}$ ). The steatotic HepG2 cells were treated with the indicated concentrations of ACF for $24 \mathrm{~h}$. (A) Oil red O staining identified red droplets in the cytoplasm of HFFA-cultured cells, and intracellular changes were observed using phase-contrast microscopy (magnification, x400). (B) TC and triglyceride TG levels were measured using a phosphoglycerol oxidase/peroxidase enzymatic assay. ${ }^{*} \mathrm{P}<0.05$, as compared with the control group; " $\mathrm{P}<0.05$, as compared with the model group. Values are presented as the mean \pm standard deviation and are representative of three independent experiments. ACF, Artemisia capillaris formula; HFFA, high free fatty acids; OA, oleic acid; PA, palm acid; TC, total cholesterol; TG, triglycerides. 

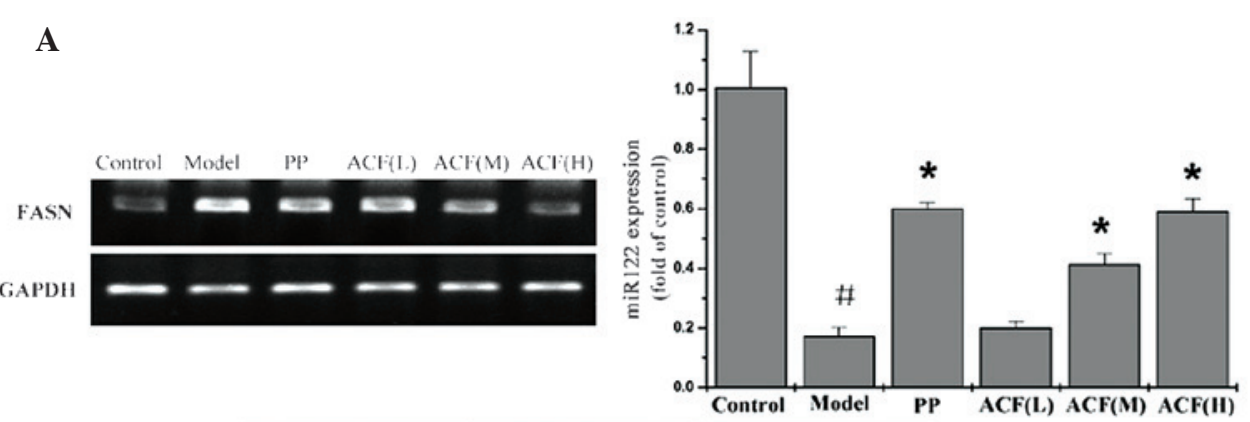

$\mathbf{B}$

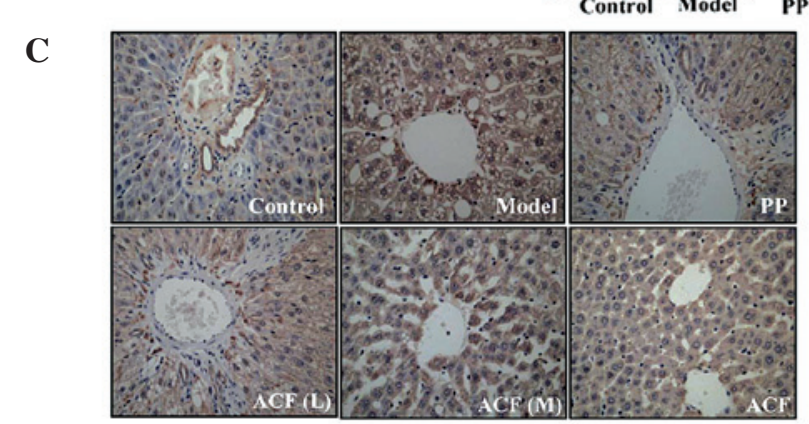

D
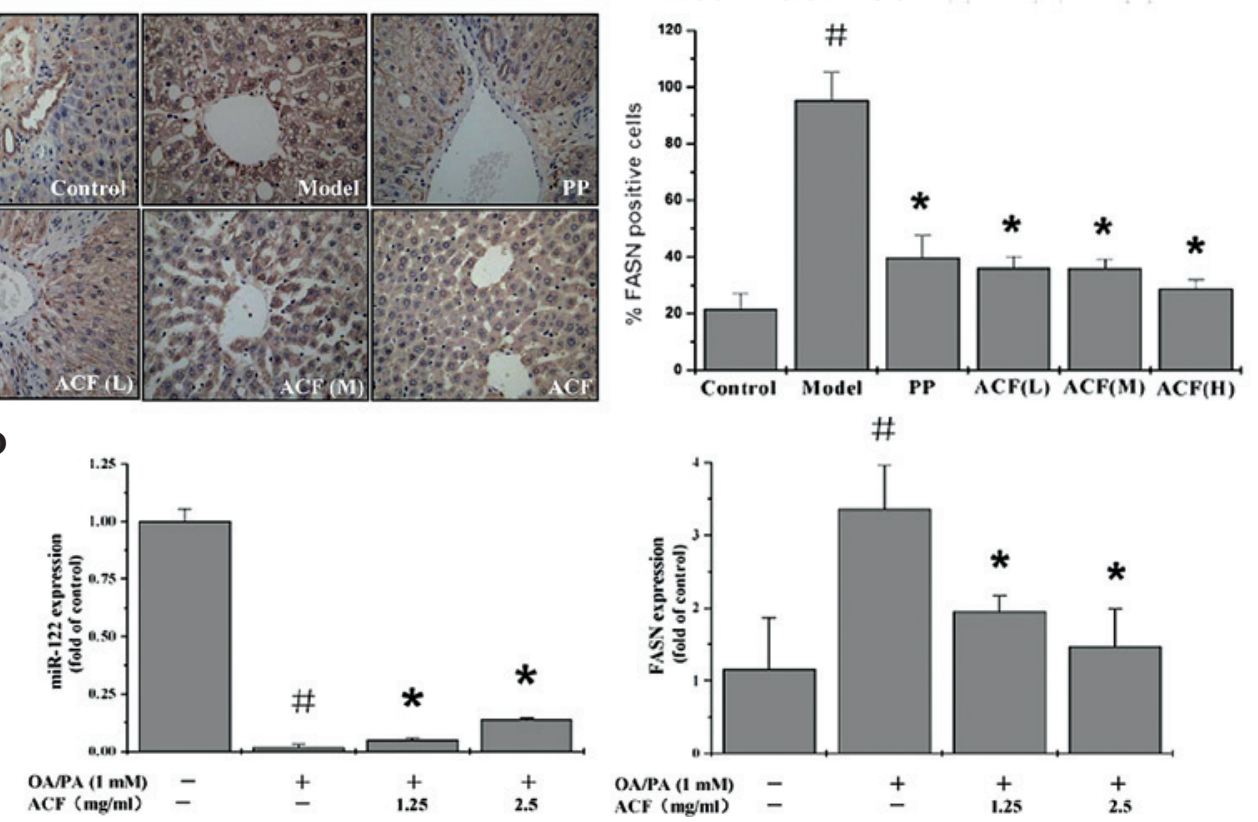

Figure 5. Treatment with ACF elevates miR-122 expression and reduces the expression levels of FASN in vivo and in vitro. (A and B) mRNA expression levels of FASN and miR-122 in HepG2 human liver carcinoma cells and rat liver tissue, as determined by RT-qPCR. (C and D) Protein expression levels of FASN, as determined by western blotting and immunohistochemical analysis. GAPDH and $\beta$-actin were used as internal controls for RT-qPCR and western blotting, respectively Magnification, $\mathrm{x} 400 .{ }^{~} \mathrm{P}<0.05$, as compared with the controls; ${ }^{*} \mathrm{P}<0.05$, as compared with the model group. Values are presented as the mean \pm standard deviation. Images are representative of six individual mice in each group, or from three independent cell-based experiments. ACF, Artemisia capillaris formula; miR-122, microRNA-122; FASN, fatty acid synthase; RT-qPCR, reverse transcription-quantitative polymerase chain reaction.

protein loading. The following day, the membranes were washed in TBS-T, and incubated with anti-rabbit HRP-conjugated secondary antibody (1:2,000 dilution) for $1 \mathrm{~h}$ at room temperature. Subsequently, the membranes were washed again in TBS-T, and the blots were visualized by enhanced chemiluminescence detection using BeyoECL Plus (Beyotime Institute of Biotechnology, Haimen, China) and visualized with ChemiDoc XRS+ (Bio-Rad Laboratories, Inc., Hercules, CA, USA) and Image Lab 3.0 (Bio-Rad Laboratories, Inc.).

Statistical analysis. All data are presented as the mean \pm standard deviation for the indicated number of independently performed experiments. All statistical analyses were performed using the SPSS package for Windows (version 16.0; SPSS, Inc., Chicago, IL, USA). Statistical analyses were performed using the Student's t-test and one-way analysis of variance. $\mathrm{P}<0.05$ was considered to indicate a statistically significant difference.

\section{Results}

Animal toxicity analysis. To determine the potential toxicity and safety of ACF, alterations in the physical appearance and body weight of the rats were assessed. As shown in Fig. 1A and B, rats fed the HFD for 12 weeks did not exhibit a significant weight change; however, the liver toxicity index was higher, as compared with that of the rats fed a normal diet. ACF supplementation to the HFD did not result in decreased body weight throughout the study. In addition, the body weight of rats administered ACF was not significantly different compared with that of the control group; however, the liver toxicity index was significantly decreased compared with that of the model rats. These results indicated that ACF was safe for administration in SD rats.

Effects of ACF on liver histology. Histological evaluation is considered to be the 'gold standard' technique for identifying the presence and severity of NAFLD (27). Therefore, in the present study liver sections were histologically evaluated, in order to assess the extent of attenuation provided by $\mathrm{ACF}$ in the development of hepatic steatosis. Representative photomicrographs of liver histology of the various groups are shown in Fig. 2. Rats fed a control diet exhibited normal liver histology; however, the rats fed a HFD exhibited elevated levels of fat accumulation and developed steatohepatitis, 
which was characterized by hepatocyte ballooning, scattered lobular inflammatory cell infiltration and inflammatory foci. Treatment with PP or ACF markedly abrogated hepatic steatosis in the HFD-fed rats, and histological grading of the liver sections confirmed that ACF treatment was able to significantly ameliorate hepatic steatosis and necroinflammation in the HFD-fed rats.

Effects of ACF on serum AST, ALT, TG, TC, HDL-C and $L D L-C$ levels. As shown in Fig. 3, rats in the model group, fed a HFD, exhibited significantly increased serum TC, TG and LDL-C levels $(\mathrm{P}<0.05)$ and reduced HDL-C levels $(\mathrm{P}<0.05)$ compared with those in the normal control group. Treatment with PP or ACF significantly suppressed the increased TC, TG and LDL-C levels induced by the HFD $(\mathrm{P}<0.05)$, and upregulated the decreased HDL-C levels; however these findings were not significant.

Effects of ACF on intracellular lipid accumulation. As shown in Fig. 4A and B, treatment of HepG2 cells with OA or PA resulted in the induction of intracellular lipid accumulation, and treatment with ACF for $24 \mathrm{~h}$ reduced the levels of fat deposition. Furthermore, TC and TG levels were also significantly downregulated following treatment with ACF.

ACF suppresses pre-miR-122 and FASN expression in vivo and in vitro. As shown in Fig. 5, mRNA and protein expression levels of FASN, as well as the expression levels of miR-122, were determined by RT-qPCR, western blotting and immunohistochemical analysis in vivo and in vitro, respectively. RT-qPCR analysis demonstrated that treatment with PP or ACF markedly increased the expression levels of miR-122 and reduced FASN mRNA expression levels (Fig. 5A and B). Western blot analysis and immunohistochemical assays indicated that the protein expression levels of FASN emulated the changes of the mRNA expression levels (Fig. 5C and D). The percentage of cells positive for FASN was significantly greater in the model group $(95.29 \pm 9.78 \%)$ compared with that of the control group $(21.59 \pm 5.44 \%)$, as determined by immunohistochemical analysis. The percentage of positive cells in the PP, ACF low-, middle- and high-dose-treated rats were $39.65 \pm 7.82,36.18 \pm 3.87,36.09 \pm 2.96$ and $28.87 \pm 3.01 \%$, respectively.

\section{Discussion}

NAFLD is a multi-step process, which is widely accepted as the hepatic manifestation of metabolic syndrome (28). However, the pathogenesis of NAFLD has yet to be clearly defined, although mitochondrial dysfunction, insulin resistance and hepatic inflammation are likely contributors (24). The present study succeeded in establishing an NAFLD model in rats and cells. The HFD-induced rat model used in the present study has more physiological similarities to human NAFLD compared with those of other models based on genetic defects or chemical-induced disease. Steatotic HepG2 cells reproduce key features of human hepatic steatosis, and therefore have been used in numerous studies $(9,23,24,25)$. These models are ideal for testing therapies to reduce the extent of NAFLD, as well as to elucidate the mechanisms of disease pathogenesis. The present study investigated the ability of ACF to prevent and treat hepatic fat accumulation in vivo and in vitro.

ACF is a Traditional Chinese Medicine formula composed of Artemisiae scopariae, Rhizoma Alismatis, Rhizoma Atractylodis Macrocephalae, Radix Bupleuri, Crateagus pinnatifida, Radix Glycyrrhizae and other components. Artemisiae scopariae is a significant traditional Chinese herb in ACF, which has been widely used as a remedy for liver diseases, including hepatitis, jaundice and fatty liver diseases (16). Previous studies have demonstrated that the aqueous extract from Artemisia capillaris Thunb. is able to inhibit the expression of inflammatory proteins, including inducible nitric oxide synthase, cyclooxygenase-2 and tumor necrosis factor- $\alpha(16,29)$. Together, these constituents have been shown to exhibit hepatoprotective effects in vivo and in vitro. Understanding the pathogenesis of liver diseases and the mechanisms underlying the effects of traditional medicines is essential for optimizing these forms of treatment for specific types of liver disease. miR-122 is highly abundant in the liver, and has garnered considerable attention for its role in the regulation of cholesterol and lipid metabolism (1). NAFLD is known to be associated with a reduced expression of hepatocyte miR-122, which subsequently alters lipid metabolism $(8,30,31)$. miR-122 has also been shown to promote adipocyte differentiation $(8,30,31)$. Numerous studies have demonstrated that miR-122 inhibition in a diet-induced mouse model of obesity results in decreased mRNA expression levels of acetyl-CoA carboxylase 2, FASN, stearoyl CoA desaturase-1 and HMG CoA reductase, and furthermore, significantly reduces the plasma cholesterol levels in these mice (8,32-35). The protein expression of FASN was increased and decreased following overexpression and silencing of miR-122 in Huh-7 cells, respectively (34).

The results of the present study demonstrated that the HFD-associated upregulation of FASN was reversed by treatment with ACF, which is a key first step in elucidating the role of miR-122 as upregulation of miR-122 may be involved in the underlying molecular mechanism. In addition, the observation that upregulation of FASN in HFD-fed rats led to an increase in fatty acid uptake and accumulation, and ultimately hepatic steatosis, provides useful insight into the mechanisms that promote the progression of associated liver diseases. The present study confirmed that miR-122 was significantly downregulated in HepG2 cells that were exposed to HFFA. Furthermore, it was demonstrated that treatment with ACF decreased the mRNA and protein expression levels of FASN, and inhibited OA/PA-induced intracellular lipid accumulation in HepG2 cells.

In conclusion, these results suggested that ACF treatment may decrease ALT, AST, TC, TG and LDL-C levels in HFD-fed rats, and TC and TG levels in steatotic HepG2 cells. Furthermore, dietary ACF reduced hepatic steatosis by upregulating the expression of miR-122 and downregulating the expression of FASN in vivo and in vitro, further supporting the role of miR-122 as a regulatory component of normal and aberrant lipid accumulation in the liver. These results suggested that ACF possesses significant potential for use in the prevention of NAFLD and non-alcoholic steatohepatitis, and that further research is required in order to clarify the 
correlation between miR-122 and its regulatory functions in lipid metabolism and liver disease.

\section{Acknowledgements}

The present study was supported by the Important Science \& Technology Specific Projects of Fujian Province (grant no. 2010YZ0001-1) and the Project Sponsored by the Education Department of Fujian Province of China (grant no.JA11139). The authors of the present study would like to thank Clarity Manuscript Consultants, LLC (Indianapolis, IN, USA) for their editorial assistance with this manuscript.

\section{References}

1. Cheung O and Sanyal AJ: Role of microRNAs in non-alcoholic steatohepatitis. Curr Pharm Des 16: 1952-1957, 2010.

2. Browning JD, Szczepaniak LS, Dobbins R, et al: Prevalence of hepatic steatosis in an urban population in the United States: Impact of ethnicity. Hepatology 40: 1387-1395, 2004.

3. Charlton M: Nonalcoholic fatty liver disease: A review of current understanding and future impact. Clin Gastroenterol Hepatol 2: 1048-1058, 2004.

4. Jun HJ, Kim J, Hoang MH and Lee SJ: Hepatic lipid accumulation alters global histone $\mathrm{h} 3$ lysine 9 and 4 trimethylation in the peroxisome proliferator-activated receptor alpha network. PLoS One 7: e44345, 2012.

5. Abdelmalek MF and Diehl AM: Nonalcoholic fatty liver disease as a complication of insulin resistance. Med Clin North Am 91: 1125-1149, 2007.

6. Jin X, Ye YF, Chen SH, Yu CH, Liu J and Li YM: MicroRNA expression pattern in different stages of nonalcoholic fatty liver disease. Dig Liver Dis 41: 289-297, 2009.

7. Lau NC, Lim LP, Weinstein EG and Bartel DP: An abundant class of tiny RNAs with probable regulatory roles in Caenorhabditis elegans. Science 294: 858-862, 2001.

8. Esau C, Davis S, Murray SF, et al: miR-122 regulation of lipid metabolism revealed by in vivo antisense targeting. Cell Metab 3 : 87-98, 2006.

9. Lin J, Liu F and Jiang Y: Antisense technologies targeting fatty acid synthetic enzymes. Recent Patents Anticancer Drug Discov 7: 198-206, 2012.

10. Liu Y, Chen SH, Jin X and Li YM: Analysis of differentially expressed genes and microRNAs in alcoholic liver disease. Int J Mol Med 31: 547-554, 2013.

11. Chang CY, Argo CK, Al-Osaimi AM and Caldwell SH: Therapy of NAFLD: Antioxidants and cytoprotective agents. J Clin Gastroenterol 40 (Suppl 1): S51-S60, 2006.

12. Caldwell SH, Argo CK and Al-Osaimi AM: Therapy of NAFLD: Insulin sensitizing agents. J Clin Gastroenterol 40 (Suppl 1): S61-S66, 2006.

13. Sanyal AJ, Campbell-Sargent C, Mirshahi F, et al. Nonalcoholic steatohepatitis:association of insulin resistance and mitochondrial abnormalities. Gastroenterology, 120(5): 1183-1192, 2001.

14. Pérez-Carreras M, Del Hoyo P, Martín MA, Rubio JC, Martín A, Castellano G, Colina F, Arenas J and Solis-Herruzo JA: Defective hepatic mitochondrial respiratory chain in patients with nonalcoholic steatohepatitis. Hepatology 38: 999-1007, 2003.

15. Ji HF, Li XJ and Zhang HY: Natural products and drug discovery. Can thousands of years of ancient medical knowledge lead us to new and powerful drug combinations in the fight against cancer and dementia? EMBO Rep 10: 194-200, 2009.
16. Zhang Y, Zhao J, Zhong X, Zheng H, Li Y, Liu L, Wan Y, Peng J and Hong Z: Ameliorative potential of Artemisia capillaris formula on nonalcoholic fatty liver disease in rats through regulation of fat metabolism. Afr J Tradit Complementary Altern Med 12: 151-161, 2015.

17. Liu X, Shen T, Wang Z, Zhaung L, Zhang W, Yu J, Wu J and Zhang S: Hepatitis E virus infection results in acute graft failure after liver transplantation: A case report. J Infect Dev Ctries 2014: 8: 245-248.

18. Ding Y, Xing J, Qiu Z, Wang Y, Zhang Y, Fang Y, Peng X, Long $Y$ and Deng P: Radioactive iodine therapy without recent antithyroid drug pretreatment for hyperthyroidism complicated by severe hyperbilirubinemia due to hepatic dysfunction: Experience of a Chinese medical center. Endocr Pract: Oct 22, 2015 (Epub ahead of print).

19. Zhao J, Zheng H, Liu Y, Lin J, Zhong X, Xu W, Hong Z and Peng J: Anti-inflammatory effects of total alkaloids from Rubus alceifolius Poir [corrected]. on non-alcoholic fatty liver disease through regulation of the NF- $\mathrm{BB}$ pathway. Int J Mol Med 31: 931-937, 2013.

20. Li Y, Zhao J, Zheng H, Zhong X, Zhou J and Hong Z: Treatment of nonalcoholic fatty liver disease with total alkaloids in Rubus aleaefolius Poir through regulation of fat metabolism. Evid Based Complement Alternat Med 2014: 768540, 2014

21. Lin J, Zhao J, Li T, Zhou J, Hu J and Hong Z: Hepatoprotection in a rat model of acute liver damage through inhibition of CY2E1 activity by total alkaloids extracted from Rubus alceifolius Poir. Int J Toxicol 30: 237-243, 2011.

22. Bonkovsky HL, Jawaid Q, Tortorelli K, et al: Non-alcoholic steatohepatitis and iron: Increased prevalence of mutations of the HFE gene in non-alcoholic steatohepatitis. J Hepatol 31: 421-429, 1999.

23. Wan Y, Liu LY, Hong ZF and Peng J: Ethanol extract of Cirsium japonicum attenuates hepatic lipid accumulation via AMPK activation in human HepG2 cells. Exp Ther Med 8: 79-84, 2014.

24. Gómez-Lechón MJ, Donato MT, Martínez-Romero A, Jiménez N, Castell JV and O'Connor JE: A human hepatocellular in vitro model to investigate steatosis. Chem Biol Interact 165: 106-116, 2007.

25. Zheng L, Lv GC, Sheng J and Yang YD: Effect of miRNA-10b in regulating cellular steatosis level by targeting PPAR-alpha expression, a novel mechanism for the pathogenesis of NAFLD. J Gastroenterol Hepatol 25: 156-163, 2010.

26. Livak KJ and Schmittgen TD: Analysis of relative gene expression data using real-time quantitative PCR and the 2(-Delta Delta C(T)) method. Methods 25: 402-408, 2001.

27. Brunt EM: Nonalcoholic steatohepatitis: Pathologic features and differential diagnosis. Semin Diagn Pathol 22: 330-338, 2005.

28. Neuschwander-Tetri BA: Nonalcoholic steatohepatitis and the metabolic syndrome. Am J Med Sci 330: 326-335, 2005.

29. Tan XJ, Li Q, Chen XH, et al: Simultaneous determination of 13 bioactive compounds in Herba Artemisiae Scopariae (Yin Chen) from different harvest seasons by HPLC-DAD. J Pharm Biomed Anal 47: 847-853, 2008.

30. Esau C, Kang X, Peralta E, et al: MicroRNA-143 regulates adipocyte differentiation. J Biol Chem 279: 52361-52365, 2004

31. Krützfeldt J, Rajewsky N, Braich R, et al: Silencing of microRNAs in vivo with 'antagomirs'. Nature 438: 685-689, 2005.

32. Chang J, Guo JT, Jiang D, Guo H, Taylor JM and Block TM: Liver-specific microRNA miR-122 enhance the replication of hepatitis $C$ virus in nonhepatic cells. J Virol 82: 8215-8223, 2008.

33. Lagos-Quintana M, Rauhut R, Yalcin A, Meyer J, Lendeckel W and Tuschl T: Identification of tissue-specific microRNAs from mouse. Curr Biol 12: 735-739, 2002.

34. Cheung O, Puri P, Eicken C, Contos MJ, Mirshani F, Maher JW, Keller JM, Min H, Luketic VA and Sanyal AJ: Nonalcoholic steatohepatitis is associated with altered hepatic microRNA expression. Hepatology 48: 1810-1820, 2008.

35. Lewis AP and Jopling CL: Regulation and biological function of the liver-specific miR-122. Biochem Soc Trans 38: 1553-1557, 2010. 